\title{
Reimagining the Sustainable and Social Justice Mathematics Classrooms in the Fourth Industrial Revolution
}

\author{
Tshele J. Moloi \\ North West University -Potchefstroom Campus \\ https://orcid.org/0000-0002-3533-2852 \\ Mogalatjane E. Matabane \\ Sol Plaatje University, South Africa \\ https://orcid.org/0000-0001-7953-6729
}

\begin{abstract}
In this conceptual paper, we provide some ways to think about sustainability and a social justice approach to teaching of mathematics in Fourth Industrial Revolution (4IR) classrooms. We imagine the mathematics classrooms in 4IR not only to provide sustainable education, but also to promote core values and qualities of social justice. The teaching of mathematics for social justice is a pedagogy that seeks to expose students to issues concerning power between social groups. It is an approach to teaching that seeks to enable students not only to maintain the status quo, but also to acquire the necessary skills to challenge current practices and offer alternatives. While there is an increasing emphasis on incorporating technology into the teaching and learning of mathematics to produce educated citizenry that will be able to function in 4IR, it is equally important that one guards against unintended consequences brought about by 4IR and not deny access to learners from a low socio-economic environment. Using critical discourse analysis, the paper argues that, as we usher 4IR into the mathematics classroom, one should also be mindful of the social skills that constitute humankind. Social skills and human capital are good foundations for understanding mathematical concepts, and critical skills need to operate effectively and productively in 4IR. Moreover, social skills such as persuasion and emotional intelligence are in higher demand across industries and in education sectors than narrow technical skills, which include, among others, programming or equipment operation and control.
\end{abstract}

Keywords: Social justice; sustainability; Fourth Industrial revolution; Mathematics teaching and learning 


\section{Introduction}

This conceptual paper attempts to reimagine the $21^{\text {st-century teaching and }}$ learning of mathematics in the Fourth Industrial Revolution (4IR). The conceptual research is a "methodology wherein the research is conducted by observing and analysing already present information on a given topic" (Polit \& Beck, 2010: p. 2). Again, Gilson and Goldberg (2015), point out that conceptual papers are without empirical data, the focus is on integration and proposing new relationships among constructs. However, it should be noted "that conceptual papers are not without empirical insights but rather build on theories and concepts that are developed and tested through empirical research" (Gilson and Goldberg, 2015:128). Participatory Virtual Community (PVC) was used observing and analysing the present information. PVC is understood as a social aggregation that emerges from the net when people carry on a public discussion long enough, with sufficient human feeling, to form a web of personal relationships in cyberspace (Kasperiuniene, 2014; Karim, 2019). Thus, as the research methodology, PVC is compatible with 4IR, in the sense that it will require new ways of thinking about technologies, thinking about ourselves, and thinking about how we govern and teach collaboratively, wisely and with the flourishing of humankind in mind (Kasperiuniene, 2014; Karim, 2019). It can be noted that both PVC and cognitive science have become a widely discussed concept describing social behaviour in sociology, business, management, communication and other social sciences. Everyday technology opens opportunities to create different kinds of content easily in the virtual space. More and more data are generated for studying users' attitudes and different behaviours (Kasperiuniene, 2014; Stauba et al., 2015).

The mathematics classroom practices must be sustainable if the 4IR must realise human potential and promote core values and qualities of social justice. According to the Department of Basic Education (2011), Dowling (2013), Gerdes (2009), and Le Roux (2008), mathematics is a human activity for all cultural groups. Thus, for mathematics classroom practice to be effective and sustainable, it is important that cultural practices and lived experiences of learners be incorporated into our teaching and learning (Dowling, 2013). This view demonstrates the need for social justice in the teaching and learning of mathematics in the 4IR era, as it echoes that mathematics relates well to our daily activities and cultural practices. Drawing from daily practices and cultural orientations while teaching mathematics in the 4IR will alleviate the problem where learners view mathematics as an ugly, dull, boring and monotonous subject to learn, with having little application to their valuable sociocultural background. In line with this argument, Le Roux (2008) asserts that it is critical to use real-world and contextual problems in school mathematics to challenge the beliefs by learners that mathematics is uninteresting and to make mathematics relevant to one's daily activities. The 4IR classroom has the potential to bring social injustices, inequalities and make the subject not accessible to underprivileged people. 


\section{Problem Statement}

It well documented in South African history that schools serving black rural students were systematically deprived quality education to keep them out of the modern economic sector (Khuzwayo, 2005; Maringe \& Osman, 2016). Access to mathematics or careers that require mathematical knowledge has been exclusive and not accessible to all (Fiske \& Ladd, 2004; Setati, 2001; Taylor, 2019). As such, a major task in post-apartheid South Africa in 1994 was to promote racial equity in education (Ladd \& Fiske, 2006; Setati, 2001; Gamede, 2017). While postapartheid South African has done a lot in addressing social injustices in education in general and mathematics education, the Fourth Industrial Revolutionary has the potential to bring imbalances of the past, if not wellmanaged. The 4IR can bring social injustices regarding the teaching and learning of mathematics and students; black rural students may be re-denied the opportunity to learn this important subject, as the content and approach are divorced from their cultural orientations and daily practices. Hence, the paper explores how to reimagine the sustainable and social justice mathematics teaching and learning in the Fourth Industrial Revolution.

\section{Pertinent Literature on mathematics for social justice in 4 IR}

Osman, Chuo, and Vebrianto (2013) argue that teaching mathematics that is divorced from learners' daily experiences contributes to social injustice in teaching and learning, as that approach to teaching tends to limit learners' access to mathematics knowledge. D'Ambrosio (2017) and Häyrinen-Alestalo (2005) further amplify this, stating that such kind of teaching creates an instability of the inner and social peace of learners regarding the comprehension of mathematical knowledge. Such instabilities can be illustrated by mathematical knowledge that is out there, foreign to their thinking, and does not tap into their social background. The ontology of mathematics is given by the discursive realm of mathematics," which have real existence in that domain and mathematical discourse as a living cultural entity creates the ontology of mathematics" (De Freitas \& Sinclair, 2013:458). According to D'Ambrosio (2017), mathematical objects are created by- made real by- the activities of mathematicians. This is the basis of social nature of mathematics (Taylor, 2019). This view is corroborated by Hasbi, Lukito and Sulaiman (2019) and Hersh (1997) suggesting that "mathematical objects are created by humans not arbitrarily" but from the needs of science and daily lives. He further argues that mathematics objects are a distinct variety of social-history and special part of culture (Hersh, 1997:22). Mathematicians often work together in groups on problems that they deem important or difficult and, in that process, they depend on other mathematicians to verify the correctness of their work and sometimes competing. Thus, mathematical knowledge and practises of mathematical community are negotiated and socially constructed (Martin, 2009; Bozkurt, 2017). This process of working together signifies that mathematics is a social activity and the subject matter of mathematics is social.

To sustain social justice in the teaching and learning of mathematics, mathematical knowledge must be inseparable from the learners' cultural background. 4IR mathematics teaching should refrain from happening as if mathematical knowledge is out there in the world; unreachable, fixed, and made 
of discrete and irrefutable pieces of information or facts (Simms, 2016; Abaté \& Cantone, 2005). For instance, the teaching of concepts such as:

$$
\text { "Solve } x \text { and } y \text { simultaneously: } 3 x=12 \text { and } 2 y+x=16 \text { " }
$$

is taught in a narrow way, where teachers follow fixed algorithmic rules that must be learnt by heart, while no relevancy to their cultural background is addressed. Such absolutist approach accepts that mathematics consists of absolute and unchallenged facts and undermine the social responsibility of mathematics in human affairs. This type of teaching of mathematical content demonstrates a high level of the social injustices that both teachers and learners had to endure in the teaching and learning of mathematics. The mathematics for social justice acknowledges the subject as "product of human inventiveness and a human activity"; (Stahl, 2013:168).

D'Ambrosio (2017) states the same argument, namely that once teachers, mathematics educators and mathematicians start teaching mathematics, something like a barrier or social injustices in the teaching of mathematics appear and obscure their concerns. They continue to teach the way they were taught and to do what they have always done. For them, their priority is to publish their research in the best journals and prepare their students or learners to get good grades by means of a variety of assessment tasks imposed upon them with less consideration of to what extent the work is closer to or divorced from learners' lived experience, thus ignoring social justice in teaching and learning of mathematics. In this way, social injustice in mathematics learning prevails forever (D’Ambrosio, 2017; Piachaud, 2008; Volmink, 1994).

As argued elsewhere (Moloi, 2013), it is critical that culture and lived experiences of learners be the starting point in our mathematics teaching, and 4IR classrooms should not be an exception. When children socialise and play cultural and indigenous games, they not only learn mathematical concepts, but they also develop a positive relationship with one another. Such games also help to "develop the intellectual curiosity and emotional well-being of young children" (Moloi, 2013:450). While there are contestations among researchers of what constitutes high-quality learning and teaching of mathematics to children, the provision and support of rich contextual play opportunities are at the centre of the debates. From both researchers and policy makers, the provision of opportunities for cultural plays is evident in the discourse on the intellectual and emotional development in young children (Hedges, 2019); Carrington, 2020). According to Panksepp and Biven (2007), one of the crucial roles of playfulness in children is the maintenance of friendships, which are, in turn, crucially important in supporting the healthy social and emotional development of young children. Moreover, tapping from the cultural background of learners when teaching mathematics helps learners to see that mathematics is not divorced from their culture and that mathematics is a social activity, not just a bunch of fixed and rigid rules where one must simply follow algorithms. When playing cultural games, children not only learn the social skills of sharing, teamwork, negotiating and resolving conflicts, but they also develop critical cognitive skills. When singing cultural songs, or clapping hands, children start to understand 
patterns, which is a key foundation of mathematics. As such, we need to cater for this human element in the teaching and learning of mathematics in the 4IR.

Moreover, mathematics is considered as the key subject in addressing $21^{\text {st }}$ century skills, such as "critical thinking, communication, collaboration and creativity" (Osman, Chuo, and Vebrianto, 2013:136). These skills symbolise the human elements. Again, these skills are embraced within technical and social skills in 4IR. According to Yenicioglua \& Suerdema, (2015:1447), technical skills are characterised by "artificial neural network systems brought together in the same way as neurons in the human brain; they are capable of decision-making by using what they learn while encountering problems". On the other hand, human beings possess social skills, such as persuasion, emotional intelligence and teaching others (Oosthuizen, 2016). These social skills are in higher demand across industries and in education sectors than narrow technical skills, which include, among others, programming or equipment operation and control (Selamat, Alias, Hikmi, Puteh \& Tapsir, 2017; Osman et al., 2013).

As a result, the mathematics community, which is not limited to teachers, lecturers, tutors and learners, need to be clear about how these skills find a place in the teaching and learning of mathematics in the digital classroom of the 4IR. While Oosthuizen (2016:6) describes 4IR as the "technological advancement that is increasingly transforming the world", humankind finds itself in an age of unprecedented digital technological progress, "which will continue to improve, bringing about not only beneficial transformations to human beings, but also socio-economic challenges and rooting out elements of humanness" (Osman et al., 2013:18). Elements of humanness might include, but are not limited to ubuntu, caring and other key soft skills that are not embraced by 4IR. Mostly, these socio-economic elements challenge human elements, and are likely to contribute to unsustainable and social inequalities and injustices in accessing mathematics epistemics. Hence, it is important that as we usher 4IR into the mathematics classroom, one should be mindful of social skills that constitute humankind. Again, D'Ambrosio (2017), and Froyd and Ohland (2013) caution us that we need to be aware of the past, when the teaching of mathematics perpetuated social injustices such as inequity, arrogance and bigotry.

The social injustices manifest in mathematics teaching instructions such as "factorise the given expression: $x^{2}+2 x$ ". Such instruction is very arrogant, because in the first instance, learners are not told why they must factorise, and how this relates to their cultural backgrounds (Abaté \& Cantone, 2005; Le Roux, 2008; Orrill, 2003). The main emphasis of the teacher lesson is only on the 'what' and 'how' part. Hence, the learners perceive mathematics as obsolete and not relevant to their daily activities. This argument is in line with the opinions raised by D'Ambrosio (2017), and Noble III and Morton (2013), namely that the type of teaching and learning of mathematics is more concerned with attaining predetermined goals of proficiency, which favour sameness and may lead to the promotion of docile citizens and irresponsible creativity; of regurgitating the raw content learnt through rote learning. Moreover, the way the assessment tasks are designed supports the reproduction of the raw mathematics content, of which such assessment tasks silence creative and critical thinking in 
mathematics teaching. Most of the questions are pitched at a low cognitive level of thinking. For instance, most tasks ask questions like, "solve the following equations: calculate the value of; or simplify the following expressions". These tasks penalise creative thinking in mathematics. These are some examples of social injustices that the teaching, learning and assessment of mathematics perpetuate.

On the other side, the National Council of Teachers of Mathematics (NCTM)'s Principles and Standards for School Mathematics (Midgett \& Eddins, 2016) and the Curriculum and Assessment Policy Statement (CAPS) (National Department of Basic Education, 2011; Orrill, 2003), demonstrate that the teaching, learning and assessment of mathematics must be done to promote a high level of critical thinking. Midgett and Eddins (2016, p. 35) argue that NCTM principles state,

"The curriculum is mathematically rich, offering students opportunities to learn important mathematical concepts and procedures with understanding ... Students confidently engage in complex mathematical tasks ... Students are flexible and resourceful problem solvers".

Again, the National Department of Basic Education states that "To develop problem-solving and cognitive skills. Teaching should not be limited to 'how' but should rather feature the 'when' and 'why' of problem types. Learning procedures and proofs without a good understanding of why they are important will leave learners ill-equipped to use their knowledge in later life" (DBE, 2011, p. 8), of which the teaching, learning and assessment rarely demonstrate these succinctly.

As D'Ambrosio (2017), Orrill (2003), and Froyd and Ohland (2005) argue, human beings should not imitate machines; rather, machines should emulate humans. Barsalou (2008) and Gerofsky (2016) illustrate this point that researchers use the grounded cognition design, a human computer (HC), and computer modelling with psychological and educational theories of learning. According to Barsalou (2008), grounded cognition theory "proposes that modal simulations, bodily states and situated action underlie cognition". Grounded cognition agrees with Mixed Reality (MR) and Embodied Mixed Reality Learning Environments. According to Lindgren and Johnson-Glenberg (2013) and Johnson-Glenberg, Birchfield, Tolentino and Koziupa (2014), respectively, there are no boundaries between cybernetic and physical learning environments where, for example, teachers and learners can use their bodies to simulate an orbit around a virtual planet and learning environment. With this argument it is possible to re-imagine the new way of teaching mathematics within the 4IR sphere, which can tap into the physical and sociocultural background of learners, and which has a huge wealth of knowledge (Yosso, 2005) in understanding complex mathematics.

In addition, Schwab (2016) points out 14 different strategies for multiplication of integers, or why $(-1)(-1)=+1$, that $4 \mathrm{IR}$ in its scale, scope and degree of complexity will be an exceptional experience that humankind has never witnessed before. It is worth noting that 4IR holds unique opportunities to improve human communication and conflict resolution. These conflict resolutions in the teaching and learning of mathematics might include the understanding of why only few learners excel in mathematics, why mathematics taught in classes does not speak to our daily events (Dehaene, 2011), whereas 
human infants and other-than-human animals develop high numeracy in their brain (Dehaene, 2011; Gerofsky, 2016).

Furthermore, in unpacking a sustainable and social justice mathematics classroom, the following key 4-type intelligence as described by Oosthuizen (2016), namely contextual intelligence, emotional intelligence, inspired intelligence and physical intelligence, which speak to social skills are needed in the 4IR. Furthermore, artificial intelligence, advanced robotics, virtual reality, and the internet of things - the more technical skills of 4IR - ought to be encompassed in a new approach to accommodating 4IR. Oosthuizen (2016), Dehaene (2011) and Johnson-Glenberg et al. (2014) consider contextual intelligence among role-players in understanding and applying mathematics content in relation to their daily contexts and its relevancy to them. Emotional intelligence includes the affective domain of role-players, who are not only limited to teachers, lecturers, tutors, learners, and community members. Emotional intelligence allows various role-players to relate with one another, such that their thoughts and feelings are well harnessed in creating new mathematical knowledge ${ }_{\iota}$ unlike the social injustices and ills that objectify participants in the teaching and learning of mathematical content knowledge (Weldeana, 2016). Again, considering inspired and physical intelligences, Oosthuizen (2016), argues that it deals with how those around us and the physical environment motivate each one of the role-players to realise a common goal. Also included are digital systems that interact with humans to achieve the expected outcome. This will assist in achieving an understanding of mathematical concepts through visual and multisensory engagements with learning technologies, and much more (Gerofsky, 2016).

\section{The theory guiding the study.}

This paper is guided by the Participatory New Product development (PNPD) as the framework. Participatory NPD by nature is integrative, collaborative and democratic, and takes social contexts into account in developing new products or process. Participants and users' needs, desires, images and feelings for crafting new products are embraced within technological design elements. All processes of Participatory NPD acknowledge participants' other roles in society, such as being a citizen, a parent, an employee, a community member, or a member of a global village with a sustainable future for the planet. Again, Participatory NPD allows all participants (including marginalised stakeholders) "to bring their own perspectives to the interactive relational exchanges in a naturalistic context" (Kasperiuniene, 2014; Stauba, Karaman, Kaya, Karapinara, \& Güven, 2015).

Nur Kareelawati (2018) adds that Participatory New Product development allows virtual and physical interactions of different role-players in the teaching of mathematics. Griffin, Dodds and Rovegno (2012) argue that often, for some of the role-players, like learners and parents, mathematical knowledge is marginalised. The system of education gives teachers authoritative powers that regard learners' minds as blank slates, of which their sociocultural context is not considered in learning mathematics (Morin and Franks, 2009). Dehaene (2011) agrees with Charalambous (2008), namely that learners and parents' 
mathematical knowledge is not recognised when one teaches mathematical concepts such as functions. Teachers can use indigenous games (Moloi, 2013), when teachers and parents play a key role in learners' mathematical knowledge. Oosthuizen (2016) posits that contextual intelligence embraces the sociocultural background in inspiring a high level of mathematical thinking.

In the context of this paper, for instance, Advanced Human-Machine and Mixed Reality (MR) (Lindgren \& Johnson-Glenberg, 2013; Vara, 2006), interfaces of the 4IR should allow the teaching and learning of mathematics be flexible and interactive in addressing the teachers and leaners' needs. The paper maintains that $4 \mathrm{IR}$ is a mixed reality (Lindgren \& Johnson-Glenberg, 2013; JohnsonGlenberg et al., 2014) to be grappled with through the creation of sustainable learning environments within the context of a $21^{\text {st-century mathematics }}$ classroom. As mathematics is conceptualised as a human activity, this theory/framework will incorporate the diverse learning of learners from various communities, especially the ones from low socio-economic strata. In some instances, past revolutions happened to marginalise their mathematics knowledge creation (D'Ambrosio, 2017). Also, their social contexts were not used to create sustainable learning environments. Rather, 4IR must embrace the participants' need and feelings in understanding mathematics key concepts, unlike where 4IR will perceived as denying access to mathematics to learners from low socio-economic strata.

\section{Discussions}

Learners usually regard the teaching of mathematics as uninteresting, obsolete and useless (D'Ambrosio, 2017; Weldeana, 2016; Abaté \& Cantone, 2005). These assertions made by learners about the teaching of mathematics are largely logical, as the content is mainly divorced from the world within which they operate. For argument's sake, learners are given mathematics problems such as the following to work out:

Work out the sum of the following mathematical expressions: $\frac{3}{4} \times \frac{2}{3}=$ ? and

$$
4 \div \frac{1}{3}=?
$$

As an explanation to the above expression to the learners, one will often hear responses where the teacher recites the algorithmic rules or definitions to work out the answer. It is common practice that the teacher will confidently sing, "To get the results of the above mathematical expression, you just multiply numerator by numerator, and thereafter multiply denominator by the denominator."

$\mathrm{He} /$ she does not provide clear justification why these rules or definitions are applied so rigidly and should be followed to the letter (Abate \& Cantone, 2005; Froyd \& Ohland, 2013). Such an approach to teaching mathematics, divorcing mathematics from social practices, denies learners the opportunity for creativity and imagination, the very core goal of learning mathematics. About imagination, Mann (2006, p. 236) cites one of the great mathematicians, Augustus De Morgan, stating that "The moving power of mathematical innovation is not reasoning but imagination." He conceptualises mathematics as a fluid domain, not a fixed 
body of knowledge to be mastered, and the essence of such fluidity is the creative application of mathematical knowledge in solving problems. This view is also shared by Gustlin (2002), suggesting that learners would not struggle so much with mathematics if the teaching were sensitive to political injustices and incorporates cultural and social contexts rich in creativity and imagination. To develop the mathematical creativity and imagination, changes in the classroom practices are necessary and it is critical to draw from learners' lived experiences in our teaching and learning of mathematics.

It is then important that mathematics teachers need to show an element of social justice by elevating the environmental and cultural background in making mathematics content easily accessible to diverse learners. Thus, the teaching of mathematics in the 4IR era should curtail these socials ills in the teaching and learning of mathematics. D'Ambrosio (2017) demonstrates that 4IR operates within multiple intelligences, for instance, emotional intelligence, spiritual (cultural) intelligence and many others, which should include the nature of mathematics. He further argues that as one teaches numbers to learners, one needs to be mindful of the fact that behind those raw numbers there is a human being who has emotions and feelings. Most importantly, as the public is aware of the achievement gaps from the plethora of studies, we should be more careful that 4IR does not take us back to the long history of mathematics being accessed by people from a certain socio-economic class. It is critical that mathematics teaching in 4IR promotes increased participation and achievement in students who historically have been marginalised by the former South African school system (Abaté \& Cantone, 2005; Orill, 2003). Our mathematics classroom in 4IR should strive to reflect social justice, equality and education, rather than maintaining the status quo.

Thus, teaching of mathematics in the 4IR must resonate within the transformative perspective of teaching mathematics; that is, moving from the traditional or Platonist approach to the Crichton approach (Abate \& Cantone, 2005). According to Weldeana (2016) and Abate and Cantone (2005), these transformative perspectives conceptualise mathematics as the product of social processes and social skills.

Thus, the re-imagined teaching of mathematics in the 4IR must take cognisance of the unjust past of teaching and learning to move into the sustainable future, which views mathematics as a human activity. D'Ambrosio (2017) coins the sustainable future of teaching mathematics for the 4IR as the "new world order", which is urgently needed, and that will embrace humanness by its nature; a new world order that will not deny and exclude the cultures of the periphery (D'Ambrosio, 2017; Orrill, 2003), which was so common in the colonial process, and still prevails in modern mathematics classroom society. In addition, Gerofsky (2016) argues that cognitive science brings together various disciplines that allow suitable new ways of teaching mathematics in a respectful way and address the social injustices embroiled in mathematics teaching. Among others, but not limited to, these disciplines that drive the 4IR include computer science, artificial intelligence, psychology, sociology, mathematics, mathematics education, philosophy of mind, anthropology, neuroscience and linguistics, and 
many more. This suggests that as we move on to 4IR in the teaching of mathematics, we need to avoid situations where human beings are objectified.

In maintaining mathematics cognitive justice to the 4IR, it is essential that technical skills be augmented with strong social and collaborative skills (Selamat et al., 2017; Dehaene, 2011) possessed by human beings. Again, Barsalou (2008) contends that grounded cognition embraces modal simulations, bodily states and situated action, which are helpful in making sure that mathematics is a human activity. Even human infants have a sense of this numerosity (Dehaene,2011). Since the advent of 4IR, it is imperative that the combination of both human and machines competencies is realised. This argument is intensified by Rubin (2017) making an assertion that it is good that computers obtain the ability to think like human beings, but humans should not think like computers, because computers do not have the social skills capital of human beings (Rubin, 2017). Human beings do guard against unintended consequences brought about by 4IR. Subsequently, proactive solutions can be embarked upon, as guided by the sustainable developmental goals (SDGs). These SDGs are the key pillars in assisting to address the education, societal and climate change issues, to mention but a few SDGs.

Furthermore, Selamat et al. (2017:22) and Brahim and Dahlan (2019:1109) define Advanced Human-Machine (AHM) interfaces as "the method of teaching and learning for modelling and simulation of the real situation." As we participate in virtual spaces; that is, teaching and learning in the digital mathematics classroom that embraces $4 \mathrm{IR}$, teachers and learners need to embrace social justice values that acknowledge one's humanness. Humanness is displayed when interaction takes place between machines and human beings (Asllani, Ettkin \& Somasundar, 2008) in the learning and teaching of mathematics in the 4IR. As pointed out by Rubin (2017), it is crucial that as we teach and learn mathematics in the 4IR, human beings should not imitate machines. This paper will also demonstrate how these social skills need to be achieved as we teach and learn mathematics in the cyberspace classroom, of which the cyberspace is characterised by Oosthuizen (2016). At the same time, one should take care not to lose the human capital. Human capital, including social skills, forms a good foundation for understanding the mathematical concepts that are needed in the 4IR.

\section{Conclusion and recommendations}

The 4IR teaching and learning of mathematics should recognise the social nature of mathematics teaching and learning. In the 4IR, teachers should not only pay attention to what mathematics is taught and how it is taught but develop critical pedagogies to start questioning what form of power and authority is used to determine what is taught. In the mathematics class, learners should be equipped to understand issues of social justice through the learning of mathematics and not just be happy with algorithms and technology. In the 4IR classroom, students should develop a kind of political and social awareness and be able to see humanity beyond the numbers and use mathematics as a tool to explore and analyse injustices in society. Thus, mathematics teaching in 4IR should disrupt the inequalities in the discourse that legitimate other forms of knowing and 
tends to subjugate the rural epistemologies and perpetuate injustices in the mathematics knowledge system.

\section{References}

Abaté, C. J., \& Cantone, K.A. (2005). An evolutionary approach to mathematics education: enhancing learning through contextual modification. Problems, Resources, and Issues in Mathematics Undergraduate Studies, 15(2), 157-176. doi:10.1080/10511970508984115

Asllani, A., Ettkin, L., \& Somasundar, A. (2008). Sharing knowledge with conversational technologies: Web logs versus discussion boards. International Journal of Information Technology and Management, 7, 217-230. doi:10.1504/IJITM.2008.016607

Barsalou, L. W. (2008). Grounded cognition. Annual Review of Psychology, 59, 617-645. doi:10.1146/annurev.psych.59.103006.093639

Bozkurt, G. (2017). Social Constructivism: Does It Succeed in Reconciling Individual Cognition with Social Teaching and Learning Practices in Mathematics. Journal of Education and Practice, 8(3), 210-218. Retrieved from https://eric.ed.gov/?id=EJ1131532

Brahim, A., \& Dahlan, A.R.A. (2019). University of the Future: Reshaping Malaysian Universities' relevance through humanising education and 4IR. (Online) International Journal of Management and Commerce Innovations, 6(2), 1106-1113. Retrieved from www.researchpublish.com (ISSN 2348-7585).

Carrington, V. (2020). Rethinking middle years: Early adolescents, schooling and digital culture. Routledge.

Charalambous, C.Y. (2008). Mathematical knowledge for teaching and the mathematical quality of instruction: An exploratory study. Cognition and Instruction, 26, 430511. doi:10.1080/07370000802177235

D'Ambrosio, U. (2017). Ethnomathematics and the pursuit of peace and social justice. ETD - Educação Temática Digital. 19,653-666. doi:10.20396/etd. v19i3.8648367

De Freitas, E., \& Sinclair, N. (2013). New materialist ontologies in mathematics education: The body in/of mathematics. Educational Studies in Mathematics, 83(3), 453-470. Retrieved from https:www.jstor.org/stable/23434902

Dehaene, S. (2011) The number sense: how the mind creates mathematics. Revised and updated edition. New York: Oxford University Press (ISBN 978-0-19-991039-7).

Department of Basic Education. (2011). Mathematics: Curriculum and Assessment Policy Statement Grades 10-12. Department of Basic Education: Pretoria.

Dowling, P. (2013). Social activity method (SAM): A fractal language for mathematics. Mathematics Education Research Journal, 25, 317-340. doi:10.1007/s13394-013-0073-8

Ernest, P. (1998). Social constructivism as a philosophy of mathematics. Suny Press.

Fiske, E. B., \& Ladd, H. F. (2004). Elusive equity: Education reform in post-apartheid South Africa. Brookings Institution Press.

Froyd, J. E., \& Ohland, M. W. (2013). Integrated engineering curriculum. Journal of Engineering Education, 94(1), 147-164. doi:10.1002/j.2168-9830.2005.tb00835.x

Gamede, N. W. (2017). Human capital development in South Africa: perspectives on education in the post-apartheid era. Master of Commerce. University of South Africa.

Gerdes, P. (2009). Exploration of technologies, emerging from African cultural practices, in mathematics (teacher) education. ZDM Mathematics Education, 42, 11-17. doi:10.1007/s11858-009-0208-2 
Gerofsky, S. (2016). Approaches to embodied learning in mathematics. In L. D. English \& D. Kirshner (eds), Handbook of international research in mathematics education. New York: Routledge.

Gilson, L. L., \& Goldberg, C. B. (2015). Editors' Comment: So, what is a conceptual paper. Group \& Organization Management (GOM), 40(2) 127-130. doi:10.1177/1059601115576425

Griffin, L., Dodds, P., \& Rovegno, I. (2012). Pedagogical content knowledge for teachers: Integrate everything you know to make students learn. Journal of Physical Education, 67(9), 57-61. doi:10.1080/07303084.1996.10604857

Gustlin, D. Z. (2012). Why can't we paint in Math class? Integrating art into the core curriculum (Doctoral dissertation). University of Florida.

Hasbi, M., Lukito, A., \& Sulaiman, R. (2019). The Realistic of Mathematic Educational Approach to Enhancing Ability Mathematical Connections. International Journal of Trends in Mathematics Education Research, 2(4), 179-183. doi:10.33122/ijtmer. $\mathrm{v} 2 \mathrm{i} 4.82$

Häyrinen-Alestalo, M. (2005). Editorial. Science Studies: a Scandinavian journal published by the Finnish Society for Science Studies, 18(2), 3-4.

Hedges, H. (2019). The "fullness of life": Learner interests and educational experiences. Learning, Culture and Social Interaction, 23, 100258. doi:10.1016/j.lcsi.2018.11.005

Hersh, R. (1997). What is mathematics, really? Oxford University Press.

Johnson-Glenberg, M. C., Birchfield, D. A., Tolentino, L., \& Koziupa, T. (2014). Collaborative embodied learning in mixed reality motion-capture environments: two science studies. Journal of Educational Psychology, 106(1), 86-104. doi: $10.1037 / \mathrm{a} 0034008$

Karim, N. K. A. (2019). Doing emotional labour in the Fourth industrial revolution (4IR): Is religious television a humanised workplace? Jurnal Komunikasi Malaysian Journal of Communication, 35(2),379- 396. doi:10.17576/JKMJC-2019-3502-23

Kasperiuniene, J. (2014). Work status and immersive presence in participatory virtual community. Role of Higher Education Institutions in Society: Challenges, Tendencies and Perspectives, 1(3), 95-100.

Khuzwayo, H. B. (2005). A history of mathematics education research in South Africa: The apartheid years. In R. Vithal, J. Adler, \& C. Keitel (Eds.), Researching mathematics education in South Africa. Perspectives, practices, and possibilities, 307328. Cape Town, South Africa: HSRC Press.

Ladd, H., \& Fiske, E. (2006). Racial equity in education: How far has South Africa come? Perspectives in Education, 24(2), 95-108.

Le Roux, K. (2008). A critical discourse analysis of a real-world problem in mathematics: looking for signs of change, Language and Education, 22(5), 307-326. doi:10.1080/09500780802152663

Lindgren, R., \& Johnson-Glenberg, M. (2013). Emboldened by embodiment: six precepts for research on embodied learning and mixed reality. Educational Researcher, 42, 445-452. doi:10.3102/0013189X13511661

Mann, E. L. (2006). Creativity: The essence of mathematics. Journal for the Education of the Gifted, 30(2), 236-260. doi: 10.4219/jeg-2006-264

Maringe, F., \& Osman, R. (2016). Transforming the post-school sector in South Africa: Limits of a skills-driven agenda. South African Journal of Higher Education, 30(5), 120-140. doi:10.20853/30-5-616 
Martin, D. B. (2009). Researching race in mathematics education. Teachers College Record, 111(2), 295-338.

Midgett, C. W., \& Eddins, K.S. (2001). NCTM's Principles and Standards for School mathematics: for Administrators. NASSP Bulletin, 85(623), 35-42. doi:10.1177/019263650108562305

Moloi, T. J. (2013). An analysis of challenges in the teaching of problem solving in Grade 10 mathematics. The Journal for Transdisciplinary Research in Southern Africa: Special edition on Sustainable Learning Environments and Social Justice, 9(3), 480-492. doi:10.4102/td.v9i3.192

Morin, J. E., \& Franks, D. J. (2009). Why do some children have difficulty learning mathematics? Looking at language for answers. Preventing school failure: Alternative Education for Children and Youth, 54(2), 111-118. doi:10.1080/10459880903217861

Noble III, R., \& Morton C. H. (2013). African Americans and Mathematics Outcomes on National Assessment of Educational Progress: Parental and Individual Influences. Journal of Child $\mathcal{E}$ Family Studies, 22, 30-37. http://dx.doi.org/10.1007/s10826-012-9640-y

Nur Kareelawati, A. K. (2018). Doing emotional labour in the fourth industrial revolution (4IR): is religious television a humanised workplace? Creative Industries International Conference (CIIC), 1-17. doi:10.17576/JKMJC-2019-3502-23

Oosthuizen, J. H. (2016). 'An assessment of 4IR-Intelligence of South African Management Practitioners through the lens of the Fourth Industrial Revolution.' In proceedings of 28th Annual Conference of the Southern African Institute of Management Scientists, University of Pretoria, South Africa, 5-7 September (ISBN: 978-0-620-71797-7).

Orrill, R. (2003). The National Council on Education and the Disciplines. USA: The National Council on Education and the Disciplines (ISBN: 0-9709547-1-9).

Osman, K., Chuo, L. \& Vebrianto, R. (2013). 21 ${ }^{\text {st }}$ Century Biology: An Interdisciplinary approach of biology, technology, engineering and mathematics education. Procedia-Social and Behavioral Sciences, 102, 188-194. doi: 10.1016/j.sbspro.2013.10.732

Panksepp, J., \& Biven, L. (2012). The archaeology of mind: Neuroevolutionary origins of human emotions. New York: WW Norton \& Company.

Piachaud, D. (2008). Social justice and public policy: a social policy perspective. Social justice and public policy: Seeking fairness in diverse societies, 33-51. ISBN: 9781861349330

Polit, D. F., \& Beck, C. T. (2010). Generalization in quantitative and qualitative research: Myths and strategies. International journal of nursing studies, 47(11), 1451-1458. doi:10.1016/j.ijnurstu.2010.06.004

Rubin, M. (2017). Full transcript: Tim Cook delivers MIT's commencement speech, 9 June. Retrieved from https://youtu.be/3NXjUpo-1q8

Schwab, K. (2016). The Fourth Industrial Revolution: what it means, how to respond. Retrieved from https://www.weforum.org/agenda/2016/01/the-fourthindustrial-revolution-what-it-means-and-how-to-respond/

Selamat, A., Alias, R.A., Hikmi, S.N., Puteh, M., \& Tapsir, S.H. (2017). Higher Education 4.0: Current Status and Readiness in the Meeting the Fourth Industrial Revolution Challenges. Redesigning Higher Education Towards Industry 4.0, Kuala Lumpur, Malaysia, 23-24 August. Retrieved from https://www.scribd.com/document/367933437/Higher-Education-4-0Current-Status-and-Readiness-in-Meeting-the-Fourth-Industrial-RevolutionChallenges-1 
Setati, M. (2001). Researching mathematics education and language in multilingual South Africa. The Mathematics Educator, 12(2), 6-20. Corpus ID: 12346983

Simms, V. (2016). Mathematical mindsets: unleashing students' potential through creative math, inspiring messages and innovative teaching. Research in Mathematics Education, 18, 1-4. doi: 10.1080/14794802.2016.1237374

Stahl, G. (2013). Translating Euclid: Designing a human-centered mathematics. Synthesis Lectures on Human-Centered Informatics, 6(2), 1-235. ISBN-13: 978-1627051354

Stauba, S., Karaman, E., Kaya, S., Karapinara, H., \& Güven, E. (2015). Artificial neural network and agility. Procedia - Social and Behavioral Sciences, 195(2015), 14771485. doi:10.1016/j.sbspro.2015.06.448

Taylor, N. (2019). Inequalities in teacher Knowledge in South Africa. In N. Spaul, J. Jansen (eds) South African Schooling: The Enigma of Inequality. Policy Implications of Research in Education,10, 263-282. Springer, Cham. doi:10.1007/978-3-03018811-5_14

Vara, A. (2006). An insider's view on science and society. Re-reading John Ziman. Journal of Science Communication, 5(4), 1-10. doi:10.22323/2.05040303

Volmink, J. (1994). Mathematics by all. In Cultural perspectives on the mathematics classroom (pp. 51-67). Springer, Dordrecht. doi:10.1007/978-94-017-1199-9_4

Weldeana, H. N. (2016). Ethnomathematics in Ethiopia: Futile or fertile for mathematics education? Momona Ethiopian Journal of Science (MEJS), 8(2), 146-167. doi: 10.4314/mejs. v8i2.4

Yenicioglua, B., \& Suerdema, A. (2015). Participatory new product development - a framework for deliberately collaborative and continuous innovation design. Procedia - Social and Behavioral Sciences, 195(2015), 1443-1452. Retrieved from http://cyberleninka.org/article/n/938944

Yosso, T. J. (2005). Whose culture has capital. A capital race theory discussion of community cultural wealth. Race Ethnicity and Education, 8(1), 69-91. doi:10.1080/1361332052000341006 